\title{
PROSPECTS OF SKQ1 (10- (6'-PLASTOQUINOYL) DECYLTRIPHENYLPHOSPHONIUM) APPLICATION FOR PREVENTION OF ORAL CAVITY DISEASES
}

\author{
M. N. Churilov ${ }^{1, *}$, Yu. V. Denisenko ${ }^{1}$, M. M. Batyushin ${ }^{2}$, A. B. Bren ${ }^{1}$ \\ and V. A. Chistyakov ${ }^{1}$ \\ ${ }^{1}$ Institute of Biology, Southern Federal University, 344090, Rostov-on-Don, Russian Federation \\ ${ }^{2}$ Department of Nephrology, Rostov State Medical University, 344022, \\ Rostov-on-Don, Russian Federation \\ *E-mail: charchangel@gmail.com
}

\begin{abstract}
Background Dental infections, like dental degradation and periodontal diseases, are the most widespread bacterial infections in humans. Due to non-life threatening nature and ubiquity, their significance in healthcare was minimized. Still, they burden the economics of healthcare and the patients. Material and methods The study of SkQ1 (10-(6'-plastoquinoyl) decyltriphenylphosphonium) antibacterial activity against Streptococcus mutans species and dental biofilm bacteria was conducted. Bactericidal and bacteriostatic effect of this substance in micromolar concentrations on pure cultures and in higher concentrations on dental plaque bacteria was established. The compound binding effect with high molecular components of human saliva was identified and quantitatively evaluated. Results The test results showed that acidic media or competing for cation-containing drugs weaken this effect. SkQ1 is potentially applicable for oral cavity infections treatment and its efficiency can be enhanced by the utilization of proper vehicles. Conclusions SkQ1 disturbs bacteria transmembrane potential, so it can be considered as an antibacterial agent that is effective against gram-positive bacteria and can increase gram-negative bacteria sensitivity to the compounds that they are often resistant to.

Keywords: SkQ1, Oral cavity pathogens, Streptococcus mutans, Saliva mucin, Antibiotics inactivation.
\end{abstract}

(C) RASĀYAN. All rights reserved

\section{INTRODUCTION}

Abbreviation SkQ stands for the class of synthetic organic molecules that consist of large organic lipophilic cation, binding hydrocarbonic linker and plant-derived antioxidant. SkQ1 (10-(6'-plastoquinoyl) decyltriphenylphosphonium) is the most well-studied compound from this family. ${ }^{1}$ SkQ family compounds (antioxidant Skulachev ions) are known primarily for their antioxidant and geroprotective effects. They are considered to be disruptors of mitochondrial respiratory chain and interceptors of reactive oxygen intermediates. These compounds are not considered, and have not been considered until now, as antibacterial agents because of precisely defined target - eukaryote mitochondrion, and application for the purpose different from microorganism growth inhibition. However, a report was published on SkQ family compounds capacity to reduce the transmembrane potential of gram-positive bacteria Bacillus subtilis, due to a mechanism similar to the mechanism of their activity in mitochondrial membranes. Still, these compounds did not exert an antibacterial effect on gramnegative bacteria Escherichia coli. ${ }^{2}$

As an antibacterial agent, SkQ1 has a number of similarities in the structure and suggested a mechanism of action. Chemically, this ion is a quaternary salt of phosphonium. Quaternary salts of phosphonium were described in the literature as promising antibacterial and antiviral agents. ${ }^{3}$ At present, their application is limited by the fact that quaternary salts of phosphonium can be toxic to humans. On the other hand, this limitation can be overcome (and it was overcome as was shown in works by Skulachev et

Rasayan J. Chem., 11(4), 1594-1603(2018)

http://dx.doi.org/10.31788/RJC.2018.1144077

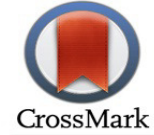


al. ${ }^{4}$ ), and the capability of these compounds to metabolize easily provides new approach to the design of antimicrobial drugs, that are not prone to the development of antibiotic resistance due to their short-term presence in the body.

By function and general mechanism of action, SkQ is a mediated ionophore (protonophore), which relates it with other ionophore antibiotics, although its structure and mechanism of action significantly differ from typical ionophores. ${ }^{5}$

Dental infections, like dental degradation and periodontal diseases, are the most widespread bacterial infections in humans. Due to non-life threatening nature and ubiquity, their significance in healthcare was minimized. Still, they burden the economics of healthcare and the patients. Dental infections treatment and their consequences are so expensive because of the lack of definite preventive measures to control bacterial pathogenesis factors. Cariogenic bacteria activity in dental plaque considerably increases the risks, associated with antimicrobial resistance of these microorganisms, including a significant increase of mutation processes rate under these conditions. ${ }^{6}$ Chlorhexidine, common in the treatment of oral cavity infections, loses its activity due to bacterial resistance development along with other antibacterial drugs. The capacity to develop vertically and horizontally transmitted antibiotic resistance to chlorhexidine and similar drugs was proved by the experiments, and this development in caries treatment is believed to be a matter of time. ${ }^{7,8}$

Since the main component of human saliva are large mucin proteins, that are capable of inactivating cation-based drugs ${ }^{9}$, and Streptococcus mutans and related groups of microorganisms are optimal model objects for dental microflora studies, the rationale for the present study was to evaluate antibacterial activity of SkQ1 against Streptococcus mutans and other dental biofilm bacteria, as well as SkQ binding capacity with large salivary proteins.

\section{Material and Methods}

\section{EXPERIMENTAL}

"Plaspomitin", SkQ1 pharmaceutical form containing the drug, and pure SkQ1 extract were used as test objects in the present study. Minimal inhibiting concentration (MIC) and minimal bactericidal concentration (MBC) were evaluated.

In vitro antibacterial activity tests were conducted with the following Streptococcus mutans strains: ATCC 25175, NTCC 11060, UA 169(2), (CU) OHZ 918. The first two strains are collection type strains of $S$. mutans, and the second two strains were isolated and kindly supplied by the Dental clinics at the medical campus of the University of Saarland (Germany).

Glucose enriched Mitis Salivarius medium was used for cultivation and count of microorganisms. In all the cases, except stock culture maintenance, the authors excluded stains and selective additives of the original formulation from the medium.

Saliva samples for binding capacity studies were taken from healthy volunteers without salivation induction.

This research has been conducted in full accordance with the World Medical Association Declaration of Helsinki. The experiments were carried out in accordance with the requirements of the European Convention for the Protection of Vertebrate Animals used for Experimental and Other Scientific Purposes (Strasbourg, 1986) and were approved by the Local Independent Ethics Committee of the Rostov State Medical University. All volunteers gave us verbal consent to the processing and promulgation of the results of the study. This was approved by the Local Independent Ethics Committee of the Rostov State Medical University.

\section{Evaluation of Minimal Inhibiting and Bactericidal Concentration}

The 24-hour culture was prepared by inoculum passage from stock culture into a test tube with the medium. Test tubes were toped up with a medium, sealed and incubated in rotation shaker-incubator at $37^{\circ} \mathrm{C}$ during continuous mixing.

The wells of 96-well sterile culture plate were filled with $75 \mu \mathrm{L}$ of the studied substance serial dilutions in sterile phosphate-buffered saline (PBS, 1.7 mmol $\mathrm{KH}_{2} \mathrm{PO}_{4}-5$ mmol $\mathrm{Na}_{2} \mathrm{HPO}_{4}$ and $0.15 \mathrm{M} \mathrm{NaCl}, \mathrm{pH} 7.2$ ). Bacterial culture was diluted by buffer solution to the density of 0.5 McFarlands units. After that, it was one hundredfold diluted with liquid nutrient medium and injected into positive control wells and test 
wells in the volume of $75 \mu \mathrm{L}$. The negative control was in wells with $150 \mu \mathrm{L}$ of sterile medium, positive control was in wells with $75 \mu \mathrm{L}$ of PBS without tested substance.

Well, plates were incubated for 46 hours in the incubator with increased content of $\mathrm{CO}_{2}$ at $37^{\circ} \mathrm{C}$. For $\mathrm{MIC}$ testing a mixture of trypan blue and crystal violet stains were added into the wells for the concentration of up to 0.0075 and 0.8 permille, respectively. Further, the well plates were incubated for 2 more hours under the monitoring of bacteria growth. MIC was defined as the minimal concentration of the substance that did not cause bacterial residue or precipitation in the wells.

For MBC testing stains were not added at the final stage. Wells content with threshold concentration of the substances, as well as the wells with minimal concentrations that allowed bacteria to grow, and the wells with concentrations from one to threefold dilutions below threshold concentration, were mixed and plated in Petri dishes that contained $50 \mu \mathrm{L}$ of solid medium Mitis salivarius. The Petri dishes were incubated for 48 hours in the same conditions as well plates and further monitored for bacterial growth. MBC was defined as the concentration that did not allow bacteria growth despite the absence of active substance in the medium.

\section{Evaluation of SkQ1 Influence on Dental Plaque Bacteria}

Two series of tests were performed for evaluation of the SkQ1 action on oral cavity microflora.

During the first test series, SkQ1 action on dental enamel surface microflora with the naturally formed bacterial film was studied. Artificial biofilm was prepared and stained by the method of Hannig et al. ${ }^{10}$ Enamel fragments, obtained from bovine cattle, was polished, fixed on the buccal side of volunteers' upper jaw and kept in these conditions for 24 hours. The extracted samples were carefully cleaned from saliva and epithelium and kept for an hour either in the active ingredient solution or in the control solution at $37^{\circ} \mathrm{C}$. The solutions consisted of PSB and $10 \%$ or $50 \%$ of saliva, isolated from macroparticles by means of centrifuging. A test solution of SkQ1 was added to the concentration of $30 \mu \mathrm{g} / \mathrm{ml}$. After the exposition, the samples were taken out and stained with fluorochromes BacLight Bacterial Viability Kit (ThermoFischer scientific, USA).

During the second test series, the samples were kept in volunteers oral cavities for 24 or 12 hours. SkQ1 was used in the form of $10 \mathrm{ml}$ "Plastomitine" solution in phosphate-buffered saline for mouth washing. 24-hour exposition included 2 mouth washing procedures (or control solution made of PBS, propylene glycol and lactic acid in the concentration equivalent to "Plastomitine") with a SkQ1 solution in a concentration of $170 \mu \mathrm{g} / \mathrm{ml}$. 12-hour exposition included 3 mouth washing procedures with the solution in a concentration of $30 \mu \mathrm{g} / \mathrm{ml}$. After that, the samples were extracted, cleaned from saliva and epithelium, and stained with fluorochromes.

Bacterial colonies on the surface of the sample were photographed by fluorescence microscope Zeiss Axiostar plus (Zeiss AG, Germany). Pictures with colonies of typical size and morphology were selected. The share of living cells in colonies was evaluated by the relation of their occupied area to the total area of the colony by "R language" software ("The R Foundation", USA). ${ }^{11}$

\section{Evaluation of SkQ Binding Capacity with Components of Saliva}

Before the test, absorbance spectrum of SkQ1 clear solution was studied, light absorption peaks were identified for this substance and molar extinction coefficient was calculated by means of spectrophotometer-fluorimeter "BMG Labtech" FLUOstar Omega. In aqueous solutions, SkQ1 has marked absorption peak in UV range with its maximum at $264 \mathrm{~nm}$ (Fig.-1). Molar extinction coefficient was equal to $\varepsilon 264=13,325 \mathrm{~L} / \mathrm{mol} / \mathrm{cm}$.

Saliva samples were cleaned from large insoluble impurities by means of centrifuging (10 minutes, $10,000 \mathrm{~g}$ ). Further, the samples were distilled in relation to fiftyfold volume of sterile bidistillate (cellulose membrane, a pore size from $12 \mathrm{kDa}$, D6066 Dialysis tubing, Sigma-Aldrich, USA) for 12 hours at $4^{\circ} \mathrm{C}$ for low-molecular substances removal. The rest saliva solution was diluted with sterile bidistillate up to protein concentration of $0.5 \mathrm{mg} / \mathrm{ml}$.

Evaluation of SkQ1 binding with components of saliva was performed by "centrifugal pumping" of these compounds solution through polyethersulphone (PES) ultrafilter-concentrator Vivaspin 500 (Sigma- 
Aldrich, USA) with $3000 \mathrm{MWCO}$ porosity. $0.5 \mathrm{ml}$ of the solution was filtered until the mass became below $10 \mu \mathrm{g}$. Substance content in the filtrate was estimated photometrically.

During dialysis concentrated SkQ1 solution was injected into $2 \mathrm{ml}$ solution aliquots of different composition: suspension of a heavy faction of saliva without alterations; with added methylene blue to the concentration up to $0.02 \%$; with added hydrogen chloride, hydrochloric acid up to $\mathrm{pH}=2$ or analog solutions that contained distillate instead of saliva. Further, $2 \mathrm{ml}$ of these solutions were dialyzed against the equal volume of distillate for 12 hours at $4^{\circ} \mathrm{C}$. This test was performed in a chamber that could contain equal volumes of solutions on each side of the membrane with $56 \mathrm{~mm}^{2}$ area and delete all the free air from both sections (Fig.-2). This installation makes it possible to reduce the tested substances dilution after dialysis, which increases the precision of further photometric measurements.

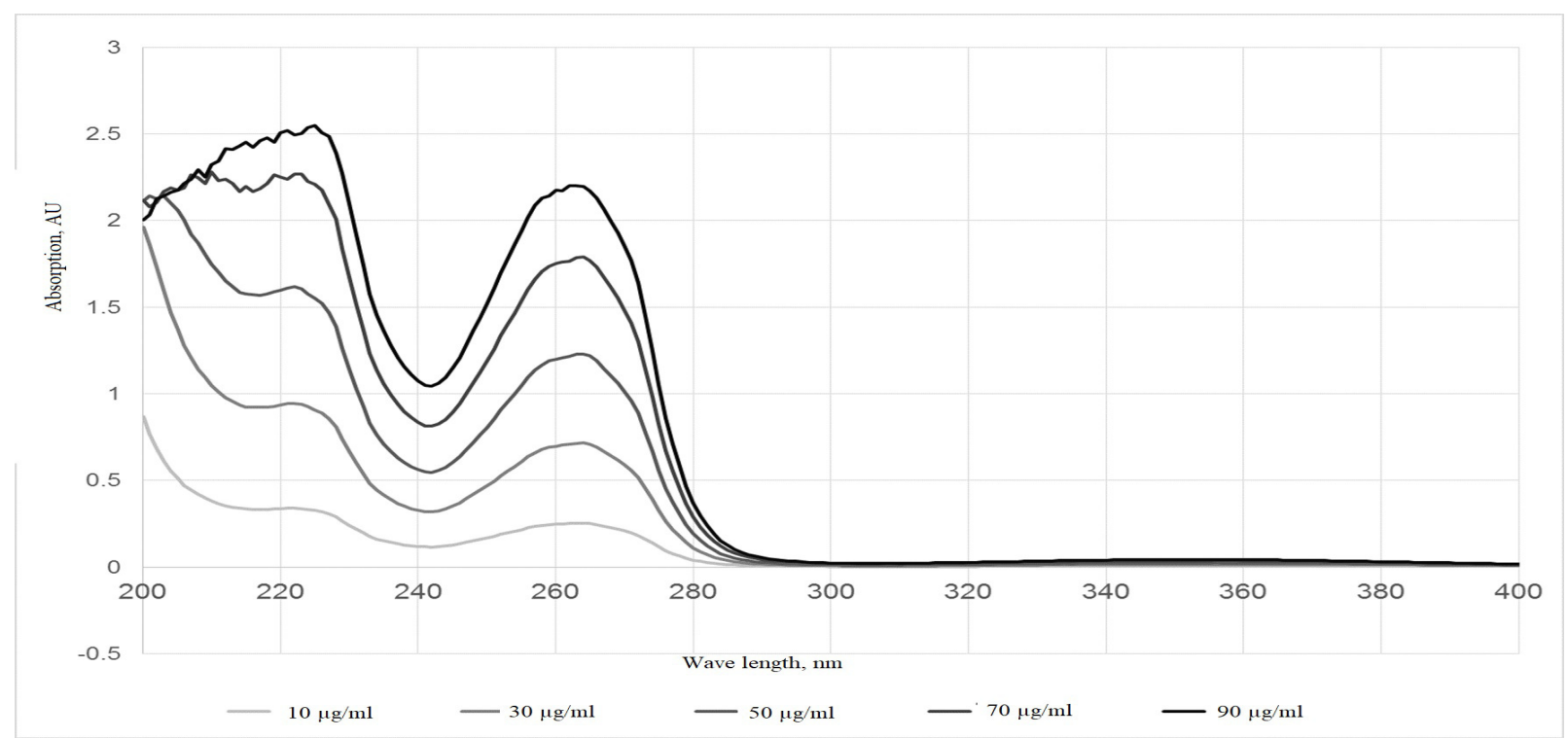

Fig.-1: SkQ1 Absorption Spectrum in UV Range. Concentration from 10 to $90 \mu \mathrm{g} / \mathrm{ml}$

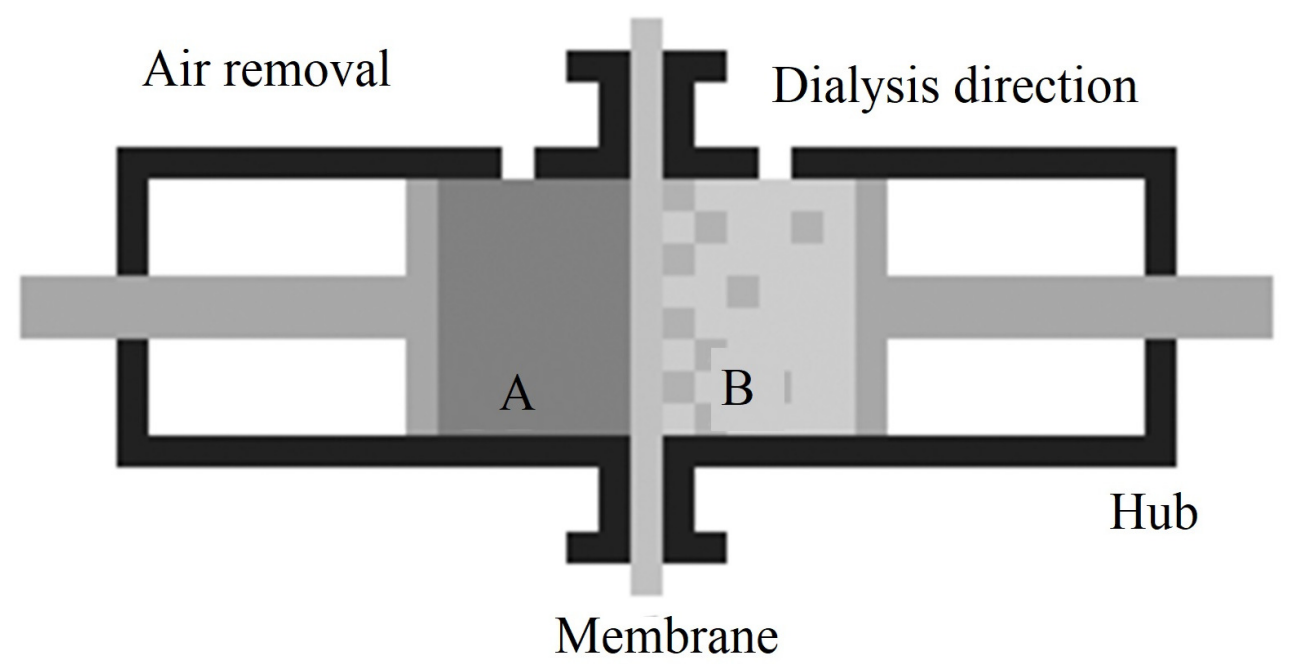

Fig.-2: Equal Volumes Dialysis Chamber. The Tested Substance is contained in Chamber A

\section{Evaluation of SkQ1 Interaction with Chitosan}

To investigate the possibility to indicate chitosan and SkQ1 in combination for caries treatment, the authors studied the influence of these substances alone and in combination on $S$. mutans growth. The authors evaluated bacterial growth curves and measured photometrically by bacteria visible light absorption at $600 \mathrm{~nm}$ wave length, using photometer FLUOstar Omega (BMG Labtech, Germany). 
RASĀYAN J. Chem.

Vol. 11 | No. 4 |1594 - 1603| October - December | 2018

Cultivation was performed in $150 \mathrm{ml}$ microplate wells under the layer of sterile mineral oil at $37^{\circ} \mathrm{C}$ for 12 hours. Liquid medium Mitis salivarius was used without selective agents. Initial culture density was equal to $5^{*} 107 \mathrm{cfu} / \mathrm{ml}$. Streptococcus mutans ATCC25175 strain and chitosan (Chitosan low molecular weight, Sigma-Aldrich, USA) were used.

\section{RESULTS AND DISCUSSION}

\section{SkQ1 Antibacterial Effect}

At present, antibiotics transporting ions (both carboxylic and channel-forming) are not used or stop being used in human diseases treatment, except for antifungal drugs like nystatin and amphotericin B that are specific to fungi cell walls. Still, they are known for significant adverse events if taken orally, so they are indicated primarily topically. ${ }^{12}$ A number of studies ${ }^{13}$ show that, in general, the existing ionophore classes do not distinguish between prokaryotic and eukaryotic cell walls, which significantly reduces their application in infections treatment. However, they exert high efficiency against gram-positive microorganisms. ${ }^{14}$ Single mechanism of resistance to ionophore antibiotic in bacteria was described, but, in general, increase of resistance to these antibiotics is not observed in anaerobic bacteria and it decreases in $\mathrm{CO}_{2}$ enriched medium. It was shown that Streptococci and GIT Coliforming bacteria did not develop resistance to some ionophores. ${ }^{12}$

Some authors in their works ${ }^{8,15}$ showed SkQ1 antibacterial action against gram-positive bacteria, still, it did not have antibacterial action against gram-negative bacteria. SkQ1 exerts activity in lipid membranes, like protonophore compounds. At the same time, gram-negative bacteria, primarily E. coli, can develop resistance to triphenylphosphonium derivatives. In this case, resistance develops due to AcrAB-TolC efflux pump of RND family that is specific to gram-negative microorganisms ${ }^{5}$. This explains the higher sensitivity of gram-positive bacteria to SkQ1. However, since the substance is membrane-targeted, SkQ1 keeps the significant load on the metabolism of gram-negative microorganisms. It should be noted that compounds, targeting transmembrane bacteria potential, can inactivate pumps of multiple antibiotic resistance. ${ }^{16}$

Although caries and dental degeneration are caused by a complicated complex of different microorganism species, the main role in these pathologies development plays Streptococcus mutans and Lactobacillus spp. - acid producing gram-positive microorganisms. Antibacterial therapy is a widely used treatment for oral cavity infections and, in particular, it is necessary for the treatment of $S$. mutans advanced infection, which is the main cariogenic microorganism. However, in recent years, because of the growth of antibiotic resistance and the appearance of drugs new side effects, it is necessary to search for new antibacterial agents for dental degeneration treatment. ${ }^{17}$

During SkQ1 antibacterial activity testing, it was established that SkQ1 inhibits the growth of $S$. mutans NTCC11060, UA 169(2) and ATCC25175 strains in concentrations higher than $2 \mu \mathrm{g} / \mathrm{ml}$ and growth of $S$. mutans (cu) OHZ 918 in concentrations higher than $1 \mu \mathrm{g} / \mathrm{ml}$ (Table-1).

Table-1: SkQ1 Activity against S.mutans Strains in vitro

\begin{tabular}{l|c|c|c}
\hline \multicolumn{1}{c|}{ S.mutans Strain } & MIC(SkQ1), $\mu \mathrm{g} / \mathrm{ml}$ & MIC, (Plastomitin), $\mu \mathrm{g} / \mathrm{ml}$ & $\mathrm{MBC}, \mu \mathrm{g} / \mathrm{ml}$ \\
\hline NTCC 11060 & $1.0-2.0$ & $1.0-2.0$ & $1.0-2.0$ \\
\hline UA 169(2) & $1.0-2.0$ & $1.0-2.0$ & $1.0-2.0$ \\
\hline ATCC 25175 & $1.0-2.0$ & $1.0-2.0$ & $1.0-2.0$ \\
\hline (cu) OHZ 918 & $0.5-1.0$ & $1.0-2.0$ & $1.0-2.0$ \\
\hline
\end{tabular}

For "Plastomitin", a pharmaceutical form of SkQ1, the measured values of MIC were similar to the values of a pure substance, except for S. mutans (cu)OHZ 918 strain, which was inhibited in a concentration higher than $2 \mu \mathrm{g} / \mathrm{ml}$. Lactic acid and propylene glycol, contained in "Plastomitin", did not inhibit bacteria growth in the respective concentrations. MBC values in all the cases were equal to MIC values.

Considering molar mass of SkQ1, its inhibiting and bactericidal concentrations range from 0.9 to $3.7 \mu \mathrm{m}$. These values are close to effective concentrations of chlorhexidine, the leading oral cavity antiseptic in 
clinical practice. Still, SkQ1 bacteriostatic activity is slightly lower than in chlorhexidine, and its bactericidal activity is higher. ${ }^{18}$

\section{SkQ1 Effect on Dental Biofilm Bacteria}

Antibacterial effect of any drug primarily depends on the capacity of the substance to reach its molecular target. Oral cavity contains substances that influence the efficiency of antibacterial agents. Primarily, this action can be exerted by salivary components that bind with SkQ1. The bonding strength depends on a number of factors, including protein concentration in saliva, $\mathrm{pH}$ level, and presence or absence of competing compounds for binding with saliva components.

In situ test results showed that samples from the first series (samples were submerged into the substance solution), treated with SkQ1 and 10\% of saliva in the solution, contained significantly higher (Wilcoxon criterion, $\mathrm{p}<0.01$ ) share of dead cells in comparison with the control (mean values $70.9 \%, 26.3 \%$, respectively). In samples treated with SkQ1 and 50\% of saliva the difference was less evident and statistically insignificant (66.7\% and $37.4 \%$, test/control) (Fig.-3).

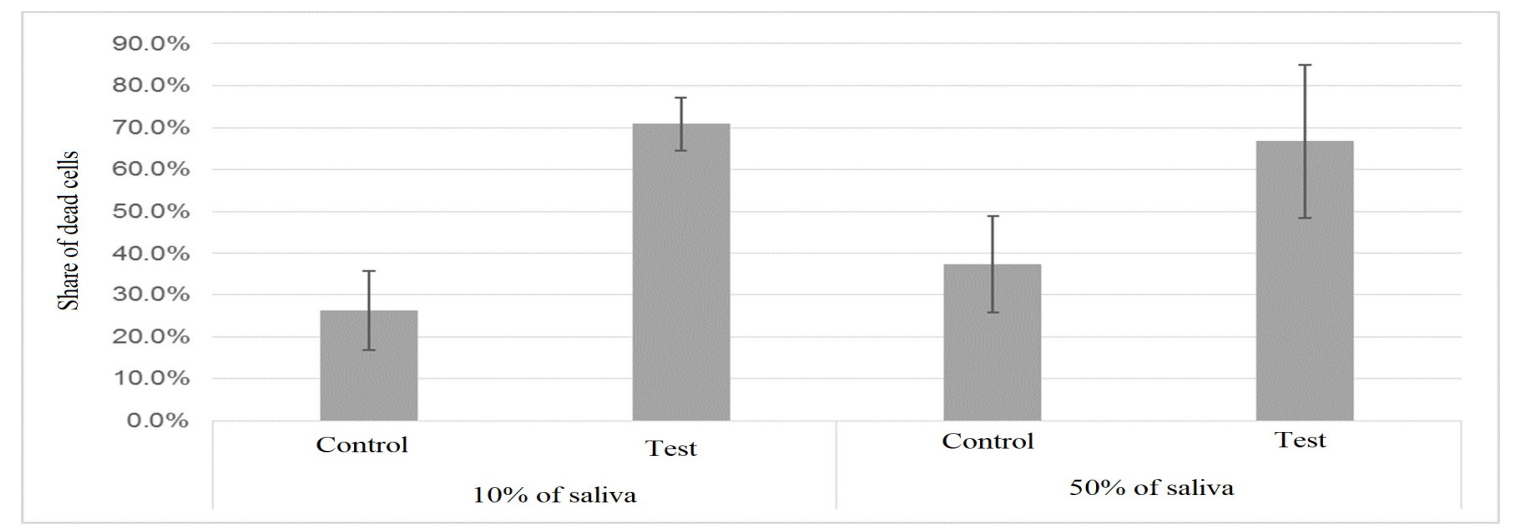

Fig.-3: Dental Biofilm Bacteria Destruction after Sample Submergence into SkQ1 Solution

The samples from the second test series (when mouth washing procedure was used) showed statistically significant difference $(\mathrm{p}<0.01)$ in dead cells share after 3 mouth wash procedures with SkQ1 solution in concentration of $340 \mu \mathrm{g} / \mathrm{ml}$ within 12 hours $(69.8 \%$ and $34.2 \%$ of dead cells in the test and control, respectively). However, when mouth washed with 2 times lower concentration $(170 \mu \mathrm{g} / \mathrm{ml})$ of the solution 2 times within 24 hours, the difference between test and control is insignificant $(48.8 \%$ and $43.4 \%$ of dead cells test/control) (Fig.-4). It should be noted that the substance in the ineffective concentration of $170 \mu \mathrm{g} / \mathrm{ml}$, that did not show activity in medium with excessive amount of saliva in oral cavity, was 5 times higher than the concentration that effectively inhibited dental biofilm bacteria in the presence of $10 \%$ of saliva and 75 times higher than $\mathrm{MBC}$ value during in vitro tests.

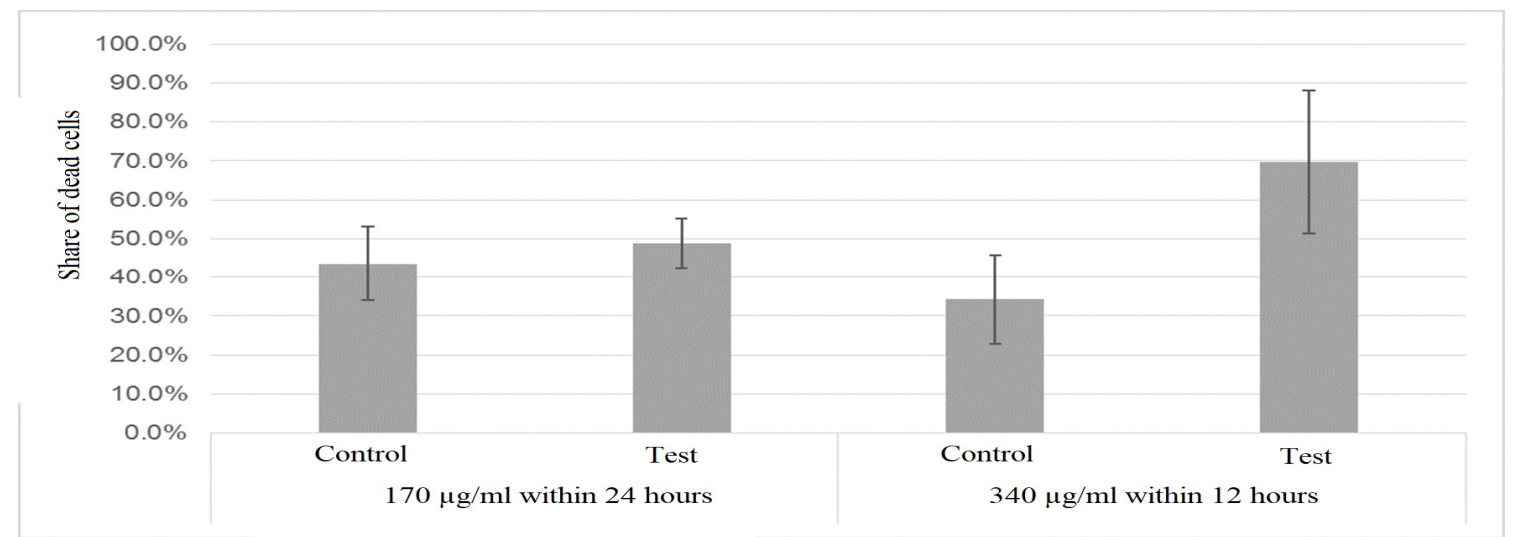

Fig.-4: Dental Biofilm Bacteria Destruction after Oral Cavity rinsing with SkQ1 Solution 
SkQ1 solution exerts a bactericidal effect on dental enamel surface microflora only at low concentration (10\%) of saliva in the solution. The skq1 solution for oral cavity washing shows an inhibiting effect in concentrations significantly higher than in the tests with samples submergence, and two times higher than in vitro tests of influence on Streptococci monoculture. Reduction of the drug effectiveness in the presence of the whole saliva and significantly higher concentrations of the drug, necessary for effective washing, can be explained by binding of the drug with saliva proteins.

\section{Interaction of SkQ1 with Components of Saliva}

The main component of human saliva protein composition is mucins (MG1, MG2), large (from 60 to 700 $\mathrm{kDa}$ ) compounds with unregular molecular mass and rich in hydroxyl-containing amino acids. These proteins can play an important role in saliva physiological function, in particular, bind alien substances. This binding event is observed in many antibacterial drugs, and has electrostatic character. Saliva mucins form stronger bonds with cation-containing drugs, like ciprofloxacin and daptomycin, and weaker bonds with anion compound.$^{9}$

SkQ1 is a strong cation compound, so the authors had to evaluate its binding capacity with components of saliva. Since saliva mucins, due to their high molecular mass, cannot transfer through the majority of cellophane dialysis membrane (that effective screen compounds up to 10-100 $\mathrm{kDa}$ ), a simple test with dialysis chambers showed that these substances can retain SkQ1. It is suggested that this effect is due to electrostatic interaction between mucins and the studied cation.

The authors also evaluated "displacement" of the studied substance by another cation antibacterial compound. Methylene blue ([7-(dimethylamino) phenothiazin-3-ylidene]-dimethylazanium chloride) was selected as a competing compound, since it is a widespread cation antiseptic, in particular, in dentistry. ${ }^{19}$ Chamber dialysis test gave the following results on the transition of a free substance through dialysis membrane from chamber A to chamber B. The values, obtained after 12-hour dialysis, were expressed in $\mu \mathrm{g}$ of SkQ1 and presented in Table-2. The yield of the substance that diffused through the dialysis membrane, in the presence of saliva components was 2 times lower than without them. In the presence of competing for compound (methylene blue) the substance yield was $13 \%$ higher and $45 \%$ higher in the acidic medium than in the respective control samples.

Table-2: SkQ1 Yield after Dialysis under Different Conditions: in the Presence and absence of Saliva Components

\begin{tabular}{l|l|l}
\hline Conditions & $\begin{array}{l}\text { Presence of Saliva } \\
\text { components in Chamber A }\end{array}$ & $\begin{array}{l}\text { SkQ1 yield in Chamber } \\
\text { B after 12-hour Dialysis, } \\
\mu \mathrm{g}\end{array}$ \\
\hline \multirow{2}{*}{ Neutral medium } & - & $36.46 \pm 0.11$ \\
\cline { 2 - 3 } & + & $17.75 \pm 0.79$ \\
\hline \multirow{2}{*}{ Acidic medium } & - & $9.56 \pm 0.09$ \\
\cline { 2 - 3 } & + & $13.84 \pm 0.13$ \\
\hline \multirow{2}{*}{$\begin{array}{l}\text { 0.02\% Methylene } \\
\text { blue }\end{array}$} & - & $20.26 \pm 0.19$ \\
\cline { 2 - 3 } & + & $22.81 \pm 0.34$ \\
\hline
\end{tabular}

Kinetics of SkQ1 diffusion through dialysis membrane (Fig.-5) showed that high acidity reduces diffusion rate regardless of the presence of saliva in the solution, which agreed with the results of the previous test. Less expressed influence on the dialysis rate was shown by methylene blue (reduced by 1.79 times). Thus, $\mathrm{pH}$ level was the factor that primarily influenced both SkQ1 bindings with components of saliva and its mobility in clear solutions.

The obtained results confirm the author's hypothesis on the electrostatic binding of SQ1 with salivary proteins that is reduced in the presence of competing for cation or in the presence of excessive amount of protons at low $\mathrm{pH}$ level. These conclusions are also confirmed by scientific literature data on the influence of low $\mathrm{pH}$ levels on mucins, that undergo conformational alterations and become more aggregated. ${ }^{20}$ Naturally, this makes it more complicated for SkQ1 molecules to bind with a reduced free area of the target protein. Clinical trials result also show a high rate of cation antibiotic (chlorhexidine) outwash from the whole saliva by acidic solution. ${ }^{21}$ 
RASĀYAN J. Chem.

Vol. 11 | No. 4 |1594 - 1603| October - December | 2018

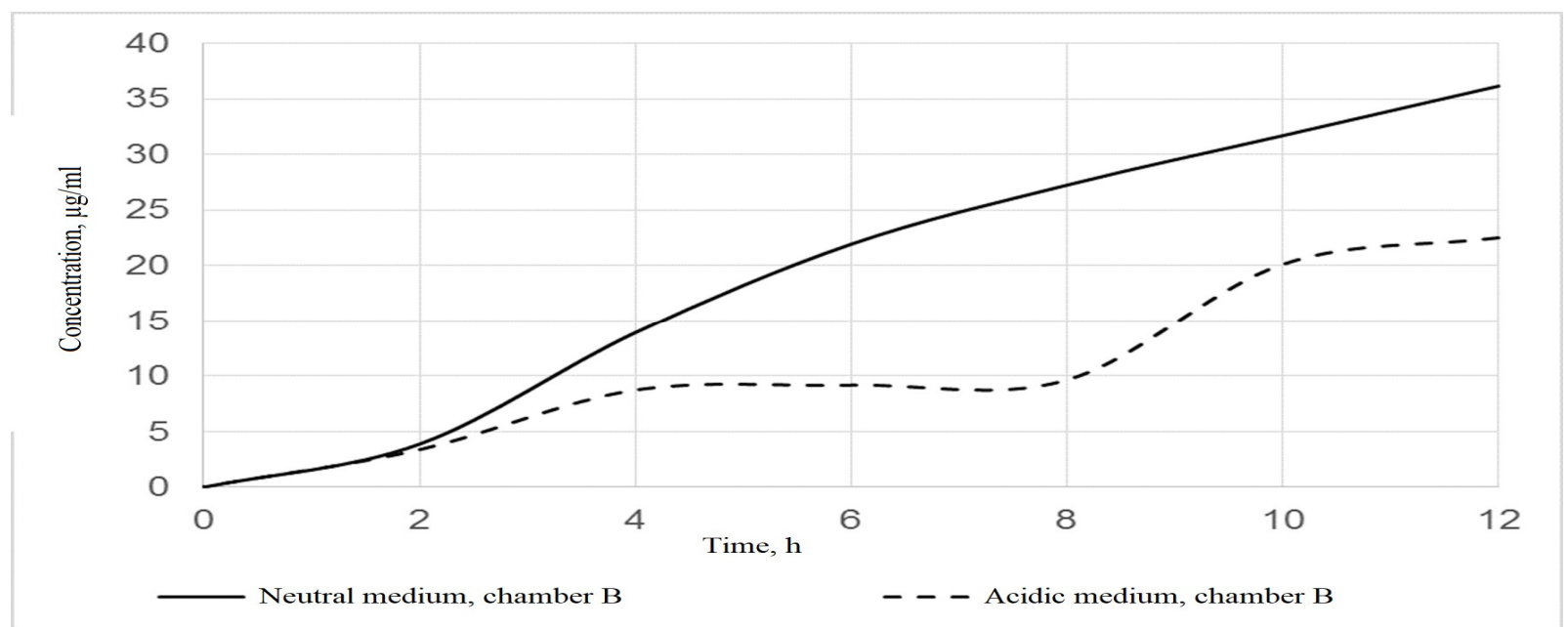

Fig.-5: Dynamics of SkQ1 Diffusion through Dialysis Membrane in Neutral and Acidic Medium

\section{Interaction of SkQ1 with Chitosan}

One of the promising polymers, applied in modern dentistry for preparation of oral cavity care products, is chitosan. Along with other properties, it exerts antibacterial effect against oral microflora. ${ }^{22,23}$

This polymer has a significant antibacterial effect and it is positively charged, which can neutralize unfavorable effects, associated with the interaction between SkQ1 and saliva components, demonstrated during the previous tests. Figure-4 shows the results of SkQ1 interaction with chitosan and its combinations with chitosan influence on the dynamics of cariogenic Streptococci growth.

The study results of dynamics of SkQ1, chitosan and their combinations activity within 12 hours showed total bacterial growth inhibition in the concentration of $2 \mu \mathrm{g} / \mathrm{ml}$ and did not show any bacteriostatic effect in the concentration of $0.2 \mu \mathrm{g} / \mathrm{ml}$ (Fig.-6), which agrees with the results of the previous tests. Chitosan in the concentration of $0.25 \%$ exerts a limited bacteriostatic effect, inhibiting bacteria growth for 9 hours, in these conditions the bacteriostatic effect of SkQ1 develops without changes (Fig.-7).

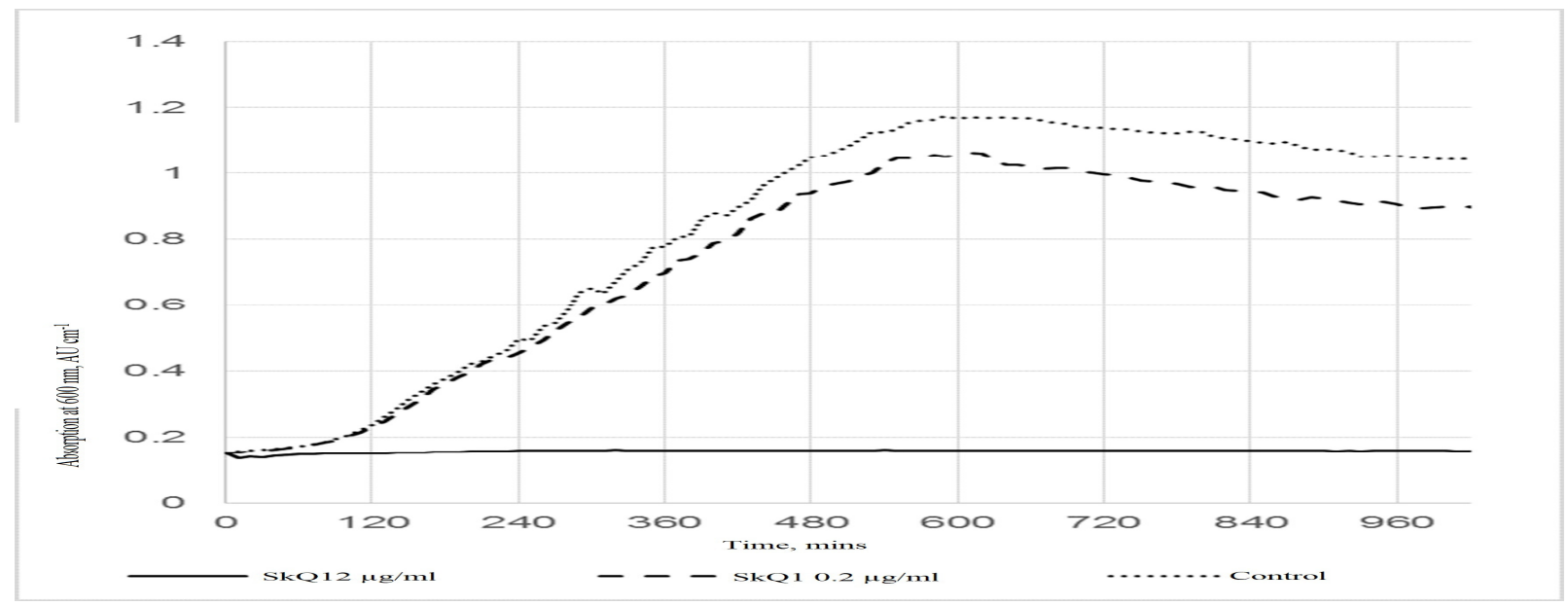

Fig.-6: Growth curve of $S$. mutans in the presence of SkQ1

Evaluation of chitosan and SkQ1 influence on $S$. mutans showed that their bactericidal and bacteriostatic effects against $S$. mutans do not reduce, when used in combination. The efficiency of these drugs in combination is significant in the development of combined drugs for oral cavity care, including those that are indicated for the prevention of cariogenic microbiota growth during teeth inter-treatment periods. This method of compounds transport is important for periodontal infections treatment, in particular, stable 
chitosan film can provide prolonged delivery of lipophilic antimicrobial agents into periodontal pocket, which is quite difficult during mouth washing with water-based preparations. ${ }^{24,25}$

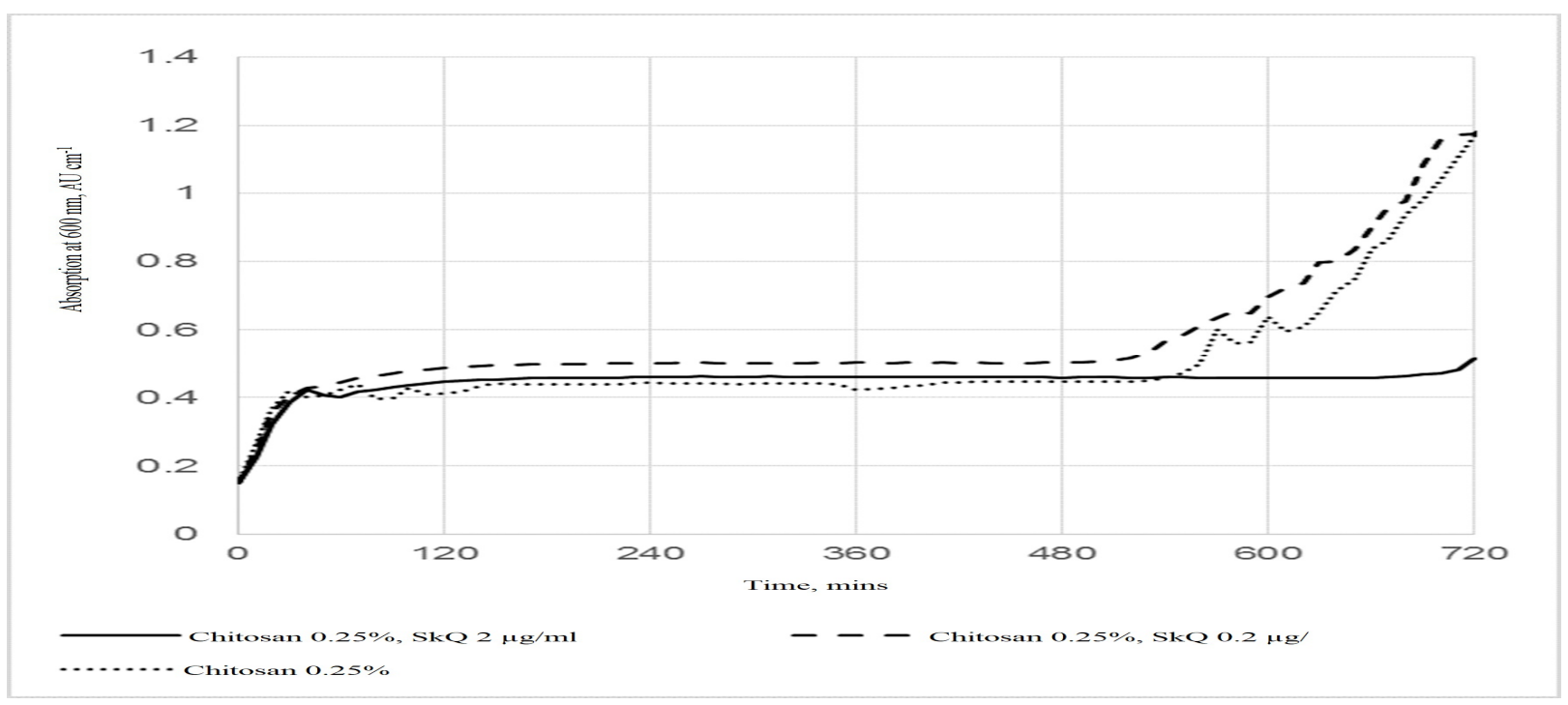

Fig.-7: Growth Curves of S. mutans in the presence of SkQ and Chitosan

\section{CONCLUSION}

The present study showed the efficiency of SkQ1 as a potential prophylactic drug during the treatment of oral cavity streptococcal infection and described the ways to avoid SkQ1 binding with large salivary proteins. SkQ1 disturbs bacteria transmembrane potential, so it can be considered as an antibacterial agent that is effective against gram-positive bacteria and can increase gram-negative bacteria sensitivity to the compounds that they are often resistant to. Thus, triphenylphosphonium-derived drugs from SkQ family can be used as antibacterial drugs of combined action that exert antibacterial, anti-inflammatory and tissue regenerative effects, that are characteristic to their class. Compatibility of SkQ1 with the vehicle agent chitosan expands its utilization in oral cavity diseases preventive care, because, on the one hand, it protects the substance from saliva flow and its components, and on the other hand, it contributes to the delayed release, which is preferable for preventive care drugs, and especially important in the conditions of constantly forming bacterial dental biofilm that is prone to antibiotic resistance development.

\section{ACKNOWLEDGMENT}

This study was supported by the Ministry of Education and Science of the Russian Federation (projects 19.6015.2017/8.9 and 6.5449.2017/6.7). The authors thank Professor Matthias Hannig, Professor Marcus Bischoff and Doctor Natalia Umanskaya, as well as all the specialists from the laboratory of the Clinics at the University of Saarland (Germany), for their help in studies of dental surface microflora. The authors thank Vladimir Petrovich Skulachev for valuable advice and expertise during the planning of tests design and discussion of study results.

\section{REFERENCES}

1. M.V. Skulachev, Y.N. Antonenko, V.N. Anisimov, B.V. Chernyak, D.A. Cherepanov, V.A. Chistyakov and E.Y. Plotnikov, Curr. Drug Targets, 12(6), 800(2011).

2. V.P. Skulachev, V.N. Anisimov and Y.N. Antonenko, Biochim Biophys Acta, 1787(5), 437(2009), DOI: $10.1016 /$ j.bbabio.2008.12.008

3. I.V. Galkina and S.N. Egorova, Medical Almanac., 3, 142(2009).

4. Y.N. Antonenko, A.V. Avetisyan and L.E. Bakeeva, Biochemistry (Mosc), 73(12), 1273(2008).

5. P.A. Nazarov, I.A. Osterman and A.V. Tokarchuk, Sci. Rep., 7(1), 1394(2017), DOI: 10.1038/s41598-017-00802-8

6. S.S. Socransky and A.D. Haffajee, Periodontol. 2000, 28(1), 12(2002).

7. G. Westergren and C.G. Emilson, Scand. J. Dent. Res., 88(3), 236(1980). 
RASĀYAN J. Chem.

Vol. 11 | No. 4 |1594 - 1603| October - December | 2018

8. H. Kitagawa, N. Izutani, R. Kitagawa, H. Maezono, M. Yamaguchi and S. Imazato, J. Dent., 47, 18(2016), DOI: 10.1016/j.jdent.2016.02.008

9. J.X. Huang, M.A.T. Blaskovich and R. Pelingon, Antimicrob Agents Chemother, 59(10), 5925(2015), DOI: $10.1128 /$ AAC.00808-15

10. C. Hannig, M. Hannig, O. Rehmer, G. Braun, E. Hellwig and A. Al-Ahmad, Arch. Oral. Biol., 52(11), 1048(2007), DOI: 10.1016/j.archoralbio.2007.05.006

11. R.C. Team, R language definition, $R$ foundation for Statistical Computing, Vienna, Austria (2000).

12. P. Butaye, L.A. Devriese and F. Haesebrouck, Clin. Microbiol. Rev., 16(2), 175(2003).

13. A. Shlosberg, S. Perl and A. Harmelin, Vet. Rec., 140(25), 643(1997), DOI: 10.1136/vr.140.25.643

14. P. Butaye, L.A. Devriese and F. Haesebrouck, J. Clin. Microbiol., 36(7), 1907(1998).

15. L.S. Khailova, P.A. Nazarov, N.V. Sumbatyan, G.A. Korshunova, T.I. Rokitskaya, V.I. Dedukhova, Y.N. Antonenko and V.P. Skulachev, Biochemistry (Mosc), 80(12), 1589(2015), DOI: 10.1134/S000629791512007X

16. K. Goldberg, H. Sarig, F. Zaknoon, R.F. Epand, R.M. Epand and A. Mor, FASEB J., 27(9), 3818(2013), DOI: 10.1096/fj.13-227942

17. J.D. Featherstone, Pediatr. Dent., 28(2), 128(2006).

18. H. Järvinen, J. Tenovuo and P. Huovinen, Antimicrob Agents Chemother., 37(5), 1158(1993).

19. I.R. Matloff, J.R. Jensen, L. Singer and A. Tabibi, Oral Surg. Oral. Med. Oral. Pathol., 53(2), 203(1982).

20. A. Gottschalk and M.A. Thomas, Biochim. Biophys. Acta, 46(1), 91(1961).

21. P. Gjermo, P. Bonesvoll and G. Rölla, Arch. Oral. Biol., 19(11), 1031(1974).

22. M. Kmiec, L. Pighinelli, M.F. Tedesco, M.M. Silva and V. Reis, Adv. Tissue Eng. Regen. Med. Open Access, 2(4), 205(2017), DOI: 10.15406/atroa.2017.02.00035

23. K. Bae, E.J. Jun, S.M. Lee, D.I. Paik and J.B. Kim, Clin. Oral. Investig., 10(2), 102(2006), DOI: 10.1007/s00784-006-0038-3

24. P. Perugini, I. Genta, B. Conti, T. Modena and F. Pavanetto, Int. J. Pharm., 252(1-2), 1(2003).

25. M.F. Rosa and F.D.B. Galvan, Periódico Tchê Química, 15(29), 136(2018).

[RJC-4077/2018] 